\title{
Hospital patient attitudes regarding cancer prevention policies focusing on processed meats: a survey of patients in high- and low-income areas
}

\author{
Neal D. Barnard ${ }^{1,2}$, Marijane Hynes ${ }^{3}$, Raymond Tư ${ }^{4}$, Lizoralia Brandon ${ }^{2}$, Elizabeth Ghandakly ${ }^{3}$, \\ Keerthi Vemulapalli ${ }^{3}$, Alyssa Burns ${ }^{2}$, Amber Nowak ${ }^{2}$ \\ ${ }^{1}$ Department of Medicine, George Washington University School of Medicine, Washington, DC, USA; ${ }^{2}$ Physicians Committee for Responsible \\ Medicine, Washington, DC, USA; ${ }^{3}$ George Washington University School of Medicine and Health Sciences, Washington, DC, USA; ${ }^{4}$ United \\ Medical Center, Washington, DC, USA \\ Correspondence to: Neal D. Barnard, MD, FACC. Adjunct Faculty, Department of Medicine, George Washington University School of Medicine, \\ 5100 Wisconsin Avenue, Suite 400, Washington, DC, USA. Email: nbarnard@pcrm.org.
}

\begin{abstract}
The American Medical Association has called on hospitals to reduce the risk of cancer, cardiovascular disease, and other health problems by eliminating processed meats from their menus. To ascertain patients' attitudes about this policy change, inpatients at 2 Washington, DC, hospitals were surveyed. One, United Medical Center (UMC), serves an economically disadvantaged area, while the other, George Washington University Hospital (GWUH), serves an economically advantaged area. The UMC population was $92 \%$ black/African American and 2\% white; the GWUH population was 56\% black/African American and $34 \%$ white $(\mathrm{P}<0.0001)$. Of 200 patients surveyed, being able to eat bacon or sausage was rated as less than important by $68.5 \%$, and as "important" or "extremely important" by $31.5 \%$. Results at the two hospitals were similar. Being able to eat these products was rated as "important" or "extremely important" by $32 \%$ and $31 \%$ at UMC and GWUH, respectively. Regarding agreement with eliminating processed meat in order to reduce cancer risk, $82.5 \%$ of participants agreed, strongly agreed, or were neutral (86\% at UMC, 79\% at GWUH). We conclude that a large majority from both hospitals supported or were neutral regarding excluding processed meats from hospital menus for cancer prevention, with no major differences between the hospitals.
\end{abstract}

Keywords: Hospital; food survey; processed meat; colorectal cancer

Received: 25 January 2020; Accepted: 22 July 2020; Published: 25 September 2020.

doi: $10.21037 /$ jhmhp-20-19

View this article at: http://dx.doi.org/10.21037/jhmhp-20-19

\section{Introduction}

In 2015, the World Health Organization determined that processed meats cause colorectal cancer (1). These products include meats that have been transformed through salting, curing, fermentation, smoking, or other processes to enhance flavor or improve preservation. Common examples include sausage, hot dogs, bacon, turkey bacon, and ham, among others. Their consumption is also associated with stomach, pancreatic, prostate, and breast cancers $(1,2)$ - presumably due to heterocyclic amines, polycyclic aromatic hydrocarbons, nitrites, and heme iron $(3,4)$-as well as cardiovascular disease and type 2 diabetes (5). Several studies have also linked processed meat consumption to chronic obstructive pulmonary disease (COPD) (6-8) and to increased hospital readmissions for COPD (9), presumably due to the tendency of nitrites and advanced glycation products found in meats to aggravate airway inflammation (10). In 2017, the American Medical Association called on hospitals to eliminate processed meats from menus for patients, staff, and visitors (11). This study aimed to understand patients' attitudes about this policy shift. We present the following article in accordance with the Standards for Reporting Qualitative Research (SRQR) checklist (available at http://dx.doi.org/10.21037/ 
jhmhp-20-19).

\section{Methods}

This in-person survey occurred at the United Medical Center and the George Washington University Hospital in Washington, DC. The former serves one of the city's most economically disadvantaged wards; the latter serves one of its most economically advantaged wards. The study was conducted in accordance with the Declaration of Helsinki (as revised in 2013). The study was deemed exempt by the George Washington University Office of Human Research Institutional Review Board (NCR191502) and the Advarra Institutional Review Board (Pro00034052), and informed consent was taken from all participants.

Participants included hospitalized patients aged 18 years or above who were able to understand English and express meaningful answers. Patients in the intensive care or psychiatric units were not included.

Individual in-person interviews were conducted by medical students, a physician, and research staff. Each participant was asked to rate the importance of each of the following while in the hospital, choosing one of the following indictors of importance: "not needed at all", "could take it or leave it", "somewhat useful", "important", or "extremely important": having Wi-Fi access, a landline telephone, being served healthful food each day, a quick discharge process upon leaving the hospital, having polite nursing staff, a private room, having flowers in the room, having access to pain medications, having pictures on the wall, having a doctor who speaks fluent English, having a daily bath, and being able to eat bacon or sausage. Only the responses related to processed meat were scored.

Participants were then read the following text: "Health authorities have found that bacon and sausage cause cancer of the colon (that is, the large intestine). If the hospital stopped serving bacon and sausage in order to help patients reduce cancer risk, would you agree or disagree with this policy?" They were asked to choose one of the following responses: "strongly agree", "agree", "neutral", "disagree", or "strongly disagree".

\section{Statistics}

Demographic data were summarized with descriptive statistics and compared between institutions using t-tests for age, Pearson chi-square for unordered categorical factors (sex, race, and ethnicity), and Mantel-Haenszel chi-square for ordered categories (expected duration of hospital stay). Exact p-values were reported when expected cell counts were small. Questionnaire responses were reported as frequencies, and distributions compared between hospitals, sexes, and black/African American versus white race groups, using the Wilcoxon rank sum test. We used the SRQR checklist when writing our report (12).

\section{Results}

In all, 209 participants provided consent, 107 at UMC and 102 at GWUH. Very few patients refused, and the number of refusals was not recorded. As shown in Figure 1, 9 patients failed to complete the survey, leaving 100 completers at each hospital. The UMC population was 92\% black/African American and 2\% white; the GWUH population was $56 \%$ black/African American and 34\% white $(\mathrm{P}<0.0001)$. Other races were represented in small numbers. Hispanics represented $2 \%$ of the UMC population and $11 \%$ of the GWUH population ( $\mathrm{P}=0.0093)$ (Table 1).

The importance of being able to eat bacon or sausage was rated as "not at all" or "could take it or leave it" or "somewhat useful" by $68.5 \%$ of participants. It was rated as "important" or "extremely important" by $31.5 \%$ (Table 2, Figure 2).

Regarding agreement with eliminating processed meat in order to reduce cancer risk, $82.5 \%$ of participants agreed, strongly agreed, or were neutral. Disagreement was reported by $16.5 \%$, and strong disagreement was reported by $1 \%$.

Results at the two hospitals were similar. The importance of being able to eat these products was rated as "not at all" or "could take it or leave it" by $54 \%$ of UMC participants and $55 \%$ of GWUH participants, and as "important" or "extremely important" by $32 \%$ and $31 \%$ at UMC and GWUH, respectively. Similar numbers supported or were neutral regarding eliminating these products in the hospital ( $86 \%$ at UMC, $79 \%$ at GWUH).

There were no major differences by sex. Analysis by race showed that black/African American participants were more likely than white participants to describe bacon and sausage as important or extremely important (36\% versus $19 \%$, $\mathrm{P}=0.0226$ ), but were also slightly more likely to support the exclusion of these products in order to help patients reduce cancer risk: $82 \%$ of black/African American participants and $80 \%$ of whites participants agreed, strongly agreed, or were neutral ( $\mathrm{P}=$ n.s.). The numbers of individuals in other races were too small for meaningful comparisons. 
Table 1 Participant characteristics

\begin{tabular}{|c|c|c|c|c|}
\hline & Total & UMC & GWUH & $P$ value \\
\hline Sex (\% female) & 53.0 & 57.0 & 49.0 & 0.257 \\
\hline Race & & & & $<0.0001$ \\
\hline Black/African American (\%) & 74.0 & 92.0 & 56.0 & \\
\hline Asian (\%) & 1.0 & 0.0 & 2.0 & \\
\hline $\mathrm{Al} / \mathrm{AN}(\%)$ & 0.0 & 0.0 & 0.0 & \\
\hline $\mathrm{NH} / \mathrm{PI}(\%)$ & 0.5 & 0.0 & 1.0 & \\
\hline$>1$ race $(\%)$ & 3.0 & 3.0 & 3.0 & \\
\hline Hispanic (\%) & 92.0 & 2.0 & 11.0 & \\
\hline Not Hispanic (\%) & 6.5 & 97.0 & 87.0 & \\
\hline No answer (\%) & 1.5 & 1.0 & 2.- & \\
\hline Expected additional hospital stay (\%) & & & & 0.0125 \\
\hline$\leq 1$ day & 31.0 & 21.0 & 41.0 & \\
\hline $2-7$ days & 40.0 & 38.0 & 42.0 & \\
\hline $8-30$ days & 5.5 & 6.0 & 5.0 & \\
\hline$>1$ month & 1.5 & 3.0 & 0.0 & \\
\hline
\end{tabular}

UMC, United Medical Center; GWUH, George Washington University Hospital; Al/AN, American Indian, Alaska Native; NH/PI, Native Hawaiian/Pacific Islander. Don't know/no answer responses were excluded in $\mathrm{P}$ value calculations.

Of the 63 participants who rated being able to eat bacon or sausage as "important" ( $\mathrm{n}=47)$ or "extremely important" $(\mathrm{n}=16), 59 \%$ either agreed, strongly agreed, or were neutral regarding eliminating these products. The remainder disagreed, except for one participant who strongly disagreed.

\section{Discussion}

In this survey of hospital inpatients, the majority considered being able to eat bacon or sausage in the hospital to be less than important, while $31.5 \%$ described it as important or extremely important. When presented with the possibility of the hospital stopping serving bacon and sausage to help patients reduce cancer risk, $82.5 \%$ supported or were neutral regarding excluding these products from the hospital menus.

In the District of Columbia, colorectal cancer incidence rates are approximately threefold higher in Ward 8, served by UMC (73.2 per 100,000), than in Ward 2, served by GWUH (25.4 per 100,000) (13). Diabetes mortality is 31.8 per 100,000 in Ward 8, compared with 6.5 per 100,000 in Ward 2 (14). Both conditions are associated with processed meat consumption.

In the present survey, however, at both hospitals, most patients viewed these products as unimportant, and a large majority supported no longer serving them in order to reduce cancer risk.

There are obvious parallels in the implementation of hospital smoking bans a generation ago. A 1978 survey at a London hospital asked patients and staff, "Do you think patients should be allowed to smoke in hospital?" Among 
Table 2 Attitudes toward processed meats served in the hospital

\begin{tabular}{|c|c|c|c|c|c|c|c|c|c|c|}
\hline & Total & \multicolumn{3}{|c|}{ Location } & \multicolumn{3}{|c|}{ Sex } & \multicolumn{3}{|c|}{ Race } \\
\hline Importance of bacon or sausage & & & & 0.3244 & & & 0.5080 & & & 0.0226 \\
\hline Not at all (\%) & 25.0 & 22.0 & 28.0 & & 21.7 & 28.7 & & 20.9 & 30.6 & \\
\hline Could take it or leave it (\%) & 29.5 & 32.0 & 27.0 & & 32.1 & 26.6 & & 27.7 & 38.9 & \\
\hline Important (\%) & 23.5 & 18.0 & 29.0 & & 23.6 & 23.4 & & 25.7 & 19.4 & \\
\hline Extremely important (\%) & 8.0 & 14.0 & 2.0 & & 8.5 & 7.4 & & 10.1 & 0.0 & \\
\hline Agreement with ban & & & & 0.5176 & & & 0.4938 & & & 0.4390 \\
\hline Strongly agree (\%) & 37.5 & 40.0 & 35.0 & & 39.6 & 35.1 & & 37.2 & 25.0 & \\
\hline Disagree (\%) & 16.5 & 13.0 & 20.0 & & 17.9 & 14.9 & & 16.2 & 19.4 & \\
\hline Strongly disagree (\%) & 1.0 & 1.0 & 1.0 & & 0.0 & 2.1 & & 1.4 & 0.0 & \\
\hline
\end{tabular}

Some groups may not sum to $100 \%$, due to rounding.

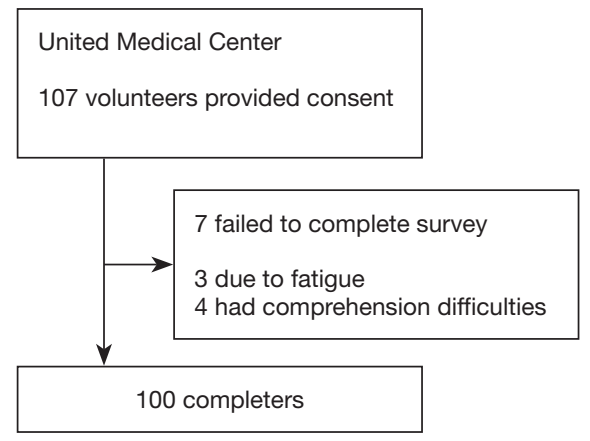

Figure 1 Enrollment of the participants and completion of the survey.

185 inpatients, $17 \%$ favored a total smoking ban, $60 \%$ favored limiting the areas or times for smoking, and 23\% favored no limits at all. Among 81 nurses and physicians included in the 1978 survey, $16 \%$ favored a total ban, $72 \%$ favored limiting the areas or times for smoking, and $12 \%$ favored no limits at all (15). A report from the Henry Ford Hospital System and the Joint Commission on this topic concluded that smoking bans had been implemented too slowly (16).

Apart from health benefits, nutritional interventions also have an economic impact. The REGARDS (REasons for Geographic and Racial Differences in Stroke) study, including 16,068 participants, found that incident heart

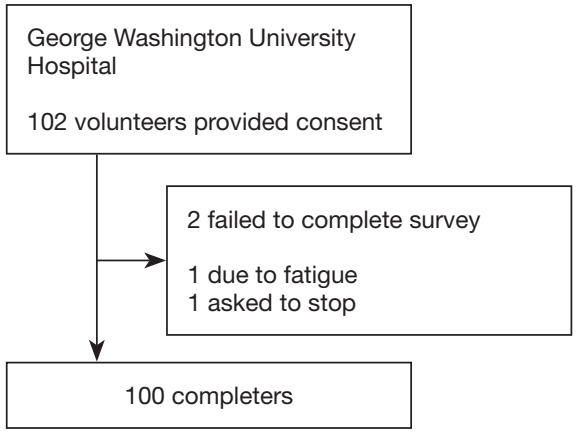

failure hospitalization —an issue highlighted by the Centers for Medicare and Medicaid Services-was $41 \%$ less likely among those adhering to diets emphasizing plant-based foods $(17,18)$. American Heart Association Guidelines recommend minimizing processed meat intake to reduce cardiovascular risk (19).

\section{Attitudes about processed meats}

Surveys have shown that reasons for continuing meat consumption include concerns about taste and nutritional adequacy, a lack of awareness of nonmeat options, and limited cooking skills $(20,21)$. While health issues play a 


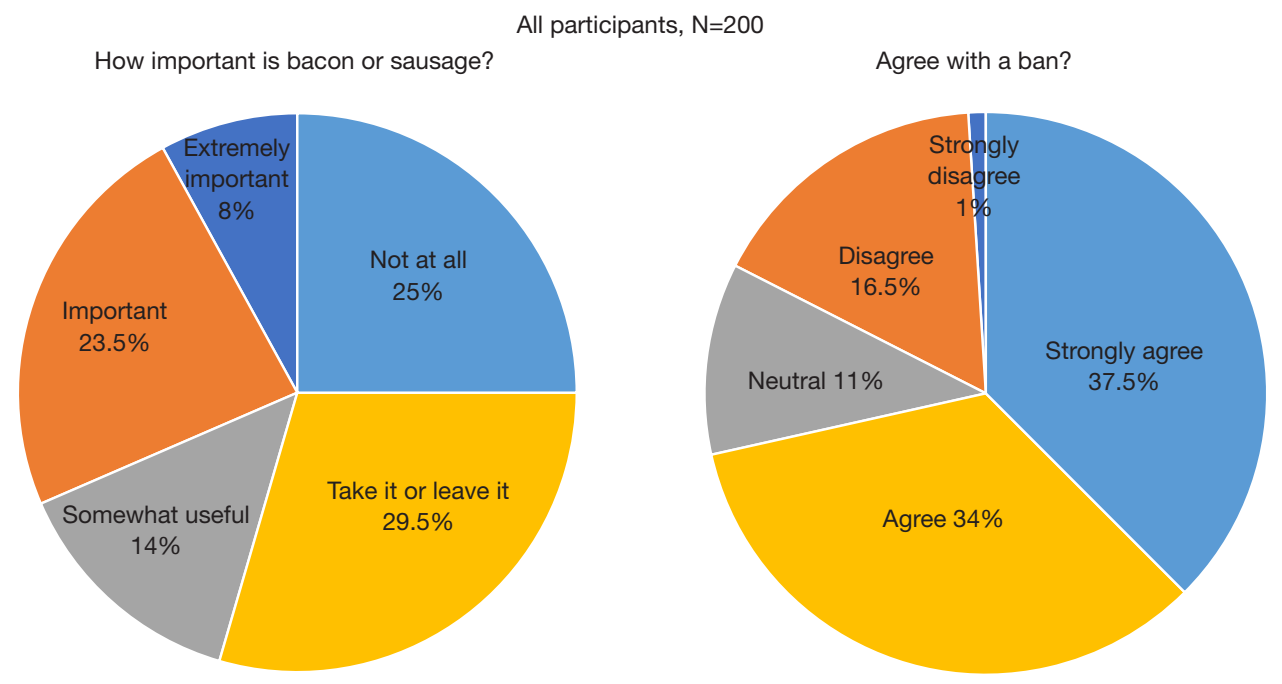

Figure 2 Responses to questions regarding (I) the importance of being able to eat bacon or sausage in the hospital and (II) agreement regarding the possibility of the hospital stopping serving bacon and sausage in order to help patients reduce cancer risk in 200 hospital inpatients.

role in consumers' decisions regarding processed meat (22); many believe that risks come only from excessive consumption (23). The present study suggests that these attitudes are not immutable. Of participants who rated being able to eat bacon or sausage in the hospital as important or extremely important, more than half supported or were neutral regarding a policy excluding these products.

Strengths of the study include an adequate sample size, economically distinct populations, and strong face validity of survey questions. Limitations include the absence of residential patients and the absence of any educational component.

In conclusion, a majority of inpatients in hospitals serving two economically different areas of Washington, DC, supported $(71.5 \%)$ or were neutral $(11 \%)$ regarding excluding process meats from hospital menus for cancer prevention, with no major differences between the hospitals.

\section{Acknowledgments}

We thank Richard Holubkov for handling statistical operations.

Funding: None.

\section{Footnote}

Reporting Checklist: The authors have completed the SRQR checklist. Available at http://dx.doi.org/10.21037/ jhmhp-20-19

Conflicts of Interest: All authors have completed the ICMJE uniform disclosure form (available at http:// dx.doi.org/10.21037/jhmhp-20-19). NDB serves without compensation as president of the Physicians Committee for Responsible Medicine and the Barnard Medical Center, organizations that promote the use of low-fat, plant-based diets and discourage the use of animal-derived, fatty, and sugary foods. He is a member of the American Medical Association and the American College of Cardiology, organizations that have called for healthy food options in hospital menus. RT reports that he is a member of the American Medical Association, which has called for healthy food options in hospital menus. $\mathrm{LB}, \mathrm{AB}$, and $\mathrm{AN}$ report that at the time of this research, they were employees of the Physicians Committee for Responsible Medicine, a nonprofit organization that promotes the use of low-fat, plant-based diets and discourages the use of animal-derived, fatty, and sugary foods, and they received compensation from the Physicians Committee for Responsible Medicine for their work on this research study. The other authors have no conflicts of interest to declare.

Ethical Statement: The authors are accountable for all aspects of the work in ensuring that questions related to the accuracy or integrity of any part of the work are appropriately investigated and resolved. The study was 
conducted in accordance with the Declaration of Helsinki (as revised in 2013). The study was deemed exempt by the George Washington University Office of Human Research Institutional Review Board (NCR191502) and the Advarra Institutional Review Board (Pro00034052), and informed consent was taken from all participants.

Open Access Statement: This is an Open Access article distributed in accordance with the Creative Commons Attribution-NonCommercial-NoDerivs 4.0 International License (CC BY-NC-ND 4.0), which permits the noncommercial replication and distribution of the article with the strict proviso that no changes or edits are made and the original work is properly cited (including links to both the formal publication through the relevant DOI and the license). See: https://creativecommons.org/licenses/by-nc-nd/4.0/.

\section{References}

1. Bouvard V, Loomis D, Guyton KZ, et al. Carcinogenicity of consumption of red and processed meat. Lancet Oncol 2015;16:1599-600.

2. Farvid MS, Stern MC, Norat T, et al. Consumption of red and processed meat and breast cancer incidence: a systematic review and meta-analysis of prospective studies. Int J Cancer 2018;143:2787-99.

3. Santarelli RL, Pierre F, Corpet DE. Processed meat and colorectal cancer: a review of epidemiologic and experimental evidence. Nutr Cancer 2008;60:131-44.

4. Demeyer D, Mertens B, De Smet S, et al. Mechanisms linking colorectal cancer to the consumption of (processed) red meat: a review. Crit Rev Food Sci Nutr 2016;56:2747-66.

5. Wolk A. Potential health hazards of eating red meat. J Intern Med 2017;281:106-22.

6. Kaluza J, Larsson SC, Linden A, et al. Consumption of unprocessed and processed red meat and the risk of chronic obstructive pulmonary disease: a prospective cohort study of men. Am J Epidemiol 2016;184:829-36.

7. Jiang R, Paik DC, Hankinson JL, et al. Cured meat consumption, lung function, and chronic obstructive pulmonary disease among United States adults. Am J Respir Crit Care Med 2007;175:798-804.

8. Varraso R, Jiang R, Barr RG, et al. Prospective study of cured meats consumption and risk of chronic obstructive pulmonary disease in men. Am J Epidemiol 2007;166:1438-45.

9. de Batlle J, Mendez M, Romieu I, et al. Cured meat consumption increases risk of readmission in COPD patients. Eur Respir J 2012;40:555-60.

10. Varraso R, Camargo C Jr. Processed meat consumption and lung health: more evidence for harm. Eur Respir J 2014;43:943-6.

11. American Medical Association. Healthy Food Options in Hospitals H-150.949. 2018. Available online: https://policysearch.ama-assn.org/policyfinder/detail/ Healthy\%20Food\%20Options\%20in\%20Hospitals\%20 H-150.949? uri=\%2FAMADoc\%2FHOD.xml-0-627.xml. Accessed September 27, 2019.

12. O'Brien BC, Harris IB, Beckman TJ, et al. Standards for reporting qualitative research: a synthesis of recommendations. Acad Med 2014;89:1245-51.

13. District of Columbia (DC) Division of Cancer Data, DC Cancer Registry, a program funded by Centers for Disease Control and Prevention (CDC). Medina R., Vargas A., Rogers K. \& Pearson-Fields, A. (2014). Burden of Cancer in the District of Columbia. Washington, DC; District of Columbia Department of Health (DOH), Community Health Administration, Bureau of Cancer and Chronic Disease. Available online: https://dchealth.dc.gov/sites/ default/files/dc/sites/doh/DOH_BurdenOfCancer_V5.pdf. Accessed October 2, 2019.

14. Diabetes in the District of Columbia. Available online: https://dchealth.dc.gov/sites/default/files/dc/sites/ doh/Diabetes\%20in\%20the\%20District\%20of\%20 Columbia\%20Fact\%20Sheet\%2011052012.pdf

15. Garratt DJ, Gough NA, Taylor EJ, et al. Smoking in hospital: a survey of attitudes of staff, patients, and visitors. J Epidemiol Community Health (1978) 1978;32:226-8.

16. Henry Ford Hospital System and the Joint Commission. Keeping your hospital property smoke-free: successful strategies for effective policy enforcement and maintenance. Available online: https://www.jointcommission.org/ assets/1/18/Smoke_Free_Brochure2.pdf

17. Lara KM, Levitan EB, Gutierrez OM, et al. Dietary patterns and incident heart failure in U.S. adults without known coronary disease. J Am Coll Cardiol. 2019;73:2036-45.

18. McIlvennan CK, Eapen ZJ, Allen LA. Hospital readmissions reduction program. Circulation 2015;131:1796-803.

19. Arnett DK, Blumenthal RS, Albert MA, et al. 2019 ACC/AHA guideline on the primary prevention of cardiovascular disease: Executive summary: A report of the American College of Cardiology/American Heart Association Task Force on Clinical Practice Guidelines. 
Circulation 2019;140:e563-e595.

20. Mullee A, Vermeire L, Vanaelst B, et al. Vegetarianism and meat consumption: A comparison of attitudes and beliefs between vegetarian, semi-vegetarian, and omnivorous subjects in Belgium. Appetite 2017;114:299-305.

21. Lea $\mathrm{E}$, Worsley A. Influences on meat consumption in Australia. Appetite 2001;36:127-36.

22. Shan LC, Henchion M, De Brún A, et al. Factors that predict consumer acceptance of enriched processed meats.

doi: 10.21037/jhmhp-20-19

Cite this article as: Barnard ND, Hynes M, Tu R, Brandon L, Ghandakly E, Vemulapalli K, Burns A, Nowak A. Hospital patient attitudes regarding cancer prevention policies focusing on processed meats: a survey of patients in high- and lowincome areas. J Hosp Manag Health Policy 2020;4:25.
Meat Science 2017;133:185-93.

23. Kovačić D, Cerjak M, Tomić M. The influence of health warnings on the future intentions of consumers-an example of red meat. In: Pospišil M, Vnučec I, Editors. 51 st Croatian and 11th International Symposium on Agriculture, February 15 - 18, 2016, Opatija, Croatia. Available online: http://sa.agr.hr/pdf/2016/sa2016_ proceedings.pdf, accessed October 5, 2019. 